ARTIGOS

\title{
Espaços do trabalho e história social na Índia
}

\section{Spaces of labour and social history in India}

Chitra Joshi

Minha preocupação com os espaços do trabalho está articulada a um presente no qual o trabalho está sendo rapidamente marginalizado e tornado invisível em cidades que foram, no passado, os centros da grande indústria na Índia. Imagens de bairros da classe trabalhadora em cidades como Ahmedabad, Bombaim, Calcutá e Kanpur são impressionantemente semelhantes: fábricas fechadas, bairros desertos e uma sensação de tristeza que parece presente em toda parte. A escuridão que cerca Girangaon (o distrito da classe trabalhadora de Bombaim), o silêncio da zona industrial ao longo do rio Sabarmati em Ahmedabad, as chaminés sem fumaça em Kanpur, a destruição dos meios de subsistência para populações inteiras, descritos em textos recentes, praticamente sugerem

\footnotetext{
Chitra Joshi é professora no Indraprastha College da Delhi University (chitrajos@gmail.com).

Texto recebido em 3 de setembro de 2008 e aprovado para publicação em 9 de janeiro de 2009.

Nota dos editores: Texto apresentado no dia 29 de agosto de 2008 na Fundação Getulio Vargas no Rio de Janeiro, como parte do ciclo de conferências proferidas pela professora Chitra Joshi no Brasil e na Argentina. Promovido pelo CPDOC/FGV e coordenado pelos professores João Maia e Paulo Fontes, este ciclo desenvolveu atividades na Unicamp, UFSC, Universidad San Martín e Universidad de Buenos Aires, além da própria FGV. Tais atividades contaram com o inestimável apoio do Sephis (The South-South Exchange Programme for Research on the History of Development). Parte das características orais da apresentação foi mantida nesta tradução. Tradução de Sérgio Lamarão. Revisão técnica de Paulo Fontes.
}

Estudos Históricos, Rio de Janeiro, vol. 22, nº 43, janeiro-junho de 2009, p. 5-30. 
que os objetos da história do trabalho estão desaparecendo. A fábrica, que esteve no centro da história do trabalho escrita na Índia até recentemente, não está mais aqui. $\mathrm{O}$ que isso significa para a escrita da história do trabalho?

O declínio no emprego industrial em lugares como Kanpur, Ahmedabad e Bombaim faz parte de uma crise mais ampla que afeta todos os grandes centros industriais da Índia. ${ }^{1}$ Desde os anos 1980, dois tipos de mudança no interior da estrutura industrial são perceptíveis. No primeiro, assistimos a um declínio de indústrias tradicionais - como as têxteis, de mineração, ferro e aço - que anteriormente dominaram o setor industrial moderno. Quanto ao segundo, houve um drástico deslocamento da produção baseada na fábrica para a produção baseada na não-fábrica, isto é, para a produção industrial em pequena escala. Indústrias tradicionais, como a de tecidos de algodão, foram sendo cada vez mais afetadas pelo crescente mercado para fibras sintéticas; a produção têxtil foi transferida das fábricas para pequenas unidades dotadas de teares mecânicos, que empregam força de trabalho barata e não regulamentada, e que se localizam longe dos velhos centros. ${ }^{2}$ Em lugares como Kanpur, as grandes fábricas de fiação e tecelagem, de propriedade do Estado, acumularam, desde o final dos anos 1970, imensas perdas causadas pela retração do mercado. Na década de 1990, as pressões advindas do lobby pró-liberalização aumentaram, e o Estado abriu mão, progressivamente, de seus compromissos em prover bem-estar. Comissões dominadas por especialistas favoráveis ao regime liberal do mercado declararam as grandes unidades têxteis decadentes e fora de qualquer possibilidade de salvação.

Até o final dos anos 1970, mais de $1 / 4$ da força de trabalho em Bombaim (hoje Mumbai) estava empregado nas fábricas de tecidos. Depois da última grande greve de trabalhadores têxteis, ocorrida em 1982-1983, mais de 100.000 trabalhadores perderam seus empregos; no início da década de 1990, a indústria representava apenas $12 \%$ da força de trabalho da cidade. Imagens da escuridão envolvendo Girangaon - o distrito da classe trabalhadora da cidade - em relato feito por Raj Chandavarkar sobre a Mumbai (Bombaim) dos anos 1990 são simbólicas da dizimação dos bairros da classe trabalhadora. $\mathrm{O}$ trabalho de Jan Breman sobre Ahmedabad (em Gujarat) retrata o silêncio que paira sobre a zona industrial ao longo das margens do rio Sabarmati, onde os trabalhadores viviam e trabalhavam, com o fechamento das fábricas (Breman, 2004: 143-144). Até os anos 1970, mais de 60 estabelecimentos têxteis empregavam cerca de 160.000 operários. ${ }^{3}$ Nos anos 1990, esses números haviam caído para 25.000 (isto é, uma queda de 84\%). A história de Kanpur, um importante centro têxtil no norte da Índia, é semelhante. Na década de 1990, a maioria das fábricas em Kanpur fechou suas portas e os trabalhadores foram empurrados para o 
trabalho informal nas ruas, como vendedores ambulantes, puxadores de riquixás e carregadores de cargas nos mercados ou apenas esperando por trabalho. Com o fechamento das fábricas de tecidos, uma cidade que costumava atrair correntes de migrantes das áreas vizinhas parece hoje invadida por uma sensação de cansaço e desesperança.

É levando em conta esse pano de fundo que procuro compreender os espaços que os trabalhadores habitaram, investigar como as atividades e as vidas dos operários marcaram esses espaços com um significado específico, e verificar o que esses espaços significam para eles. Essa investigação requererá, também, que repensemos muitas das categorias espaciais por intermédio das quais os historiadores do trabalho na Índia refletiram sobre as histórias do trabalho, e que empurremos as fronteiras da história do trabalho para além dos limites da fábrica.

\section{Espaços de trabalho}

A história do trabalho que emergiu na Índia a partir dos anos 1950 centrou seus esforços, predominantemente, na força de trabalho fabril. Ao longo dos últimos 50 anos, os historiadores trabalharam com as diferentes regiões industriais indianas e escreveram monografias sobre a força de trabalho operária de vários setores. Morris D. Morris e Raj Chandavarkar reconstruíram a história dos trabalhadores das fábricas de tecidos de algodão de Bombaim, Dipesh Chakrabarty escreveu sobre as indústrias de juta em Bengala, Sujata Patel e Jan Breman investigaram os operários de tecidos de Ahmedabad e Chitra Joshi procurou recuperar as vidas dos trabalhadores têxteis de Kanpur, uma cidade no norte da Índia. Hoje, fica claro que precisamos ir além da abordagem fabricocêntrica, e olhar para os espaços de trabalho fora da fábrica. No entanto, pretendo começar argumentando que, para compreender as histórias de trabalho, a fábrica continua sendo importante como espaço, continua sendo importante nas vidas e na memória dos trabalhadores que trabalharam nas fábricas e agora não têm trabalho, e continua sendo importante para a pesquisa do historiador. Precisamos compreender o que as fábricas, como lugar, representam para as vidas dos trabalhadores e para o espaço urbano no qual estão localizadas e o que a sua ausência significa para a cultura política da cidade.

Nos relatos típicos sobre o trabalho, o espaço de trabalho - a fábrica simboliza o encontro do migrante rural com a modernidade. Nos textos sobre o mundo do trabalho na Índia nos anos pós-independência, nas décadas de 1950 e 1960, a fábrica aparecia como um local onde os tabus do puro e do impuro - as práticas através das quais os grupos de casta e de comunidade eram incluídos 
ou excluídos dos espaços sociais - tornavam-se mais frágeis. Esse era um espaço onde os trabalhadores ficavam juntos, transcendendo as barreiras de região e comunidade, onde novos regimes de tempo e disciplina evoluíam ao longo dos tempos e onde os camponeses eram remodelados como operários fabris.

Um clássico nesse gênero é The Emergence of an Industrial Labour Force, de Morris David Morris. A fábrica, no relato de Morris, desponta como um espaço moderno de duas maneiras: por permitir o enfraquecimento de laços pré-modernos mais antigos de casta e comunidade e por ser organizada segundo certos princípios econômicos racionais. Com base em uma análise atenta de dados de casta, Morris argumenta que trabalhadores de diferentes castas trabalhavam lado a lado em diversas seções nos estabelecimentos fabris de Bombaim: "Parece-me seguro afirmar que, embora houvesse, certamente, agrupamentos por casta nas fábricas de Bombaim, eles não eram exclusivos e não impediam que membros de diferentes jatis [castas] trabalhassem lado a lado, uns com os outros" (Morris, 1965). Os argumentos de que os trabalhadores de certas castas "intocáveis" estavam excluídos de ocupações como a tecelagem são negados por Morris com base no fato de que isso representava uma tentativa dos trabalhadores de casta elevada - que haviam ingressado mais cedo no trabalho fabril - de preservar para si as ocupações mais bem pagas como a tecelagem, excluindo os que haviam chegado mais tarde nas fábricas (Morris, 1965: 79). A frouxidão "aparente" das regras e regulamentos, comparada à situação em Lancashire, propõe Morris, tem de ser encarada em termos do contexto específico do trabalho nos estabelecimentos fabris de Bombaim: "O cálculo econômico racional encorajava o que, para muitos observadores, parecia ser um sistema de uso e disciplina do trabalho completamente ultrapassado" (Morris, 1965: 203-204). Nesse cenário, a fábrica constituía um domínio de razão e racionalidade, um espaço onde os princípios da modernidade eram revelados. Mesmo a persistência das formas tradicionais, como os sistemas de recrutamento e a disciplina do trabalho, pode ser entendida, de acordo com Morris, apenas como produto de um mundo da razão. Elas sobreviviam porque os empregados atendiam às necessidades dos empregadores, adequando-se aos seus (dos empregadores) cálculos econômicos racionais.

Este argumento modernizador é colocado de cabeça para baixo por Dipesh Chakrabarty. As fábricas de sacaria de juta dos séculos XIX e XX em Bengala, afirma Chakrabarty, não apresentavam nenhum dos pré-requisitos essenciais de uma fábrica moderna. Os regulamentos, os códigos fabris, as noções de contrato e legalidade - essenciais para o funcionamento de uma moderna empresa industrial - estavam ausentes. A relação dos operários dessas fábricas com o trabalho e a maquinaria, assegura Chakrabarty, não era regulada pela razão ou pela ciência: 
[Ela] foi mediada pela concepção que os camponeses do norte da Índia tinham de suas ferramentas, segundo a qual as ferramentas adquiriam, com frequência, qualidades mágicas e divinas. Essa relação era determinada mais por uma visão religiosa do que pela "ciência", com a diferença que, numa fábrica de sacaria de juta, as ferramentas do trabalhador eram, de longe, mais poderosas e malignas do que os implementos dos camponeses. (Chakrabarty, 1989: 89)

Chakrabarty prossegue, descrevendo os rituais de sacrifício animal existentes em algumas daquelas fábricas:

Em certas fábricas de sacaria de juta perto de Calcutá, os mecânicos costumavam sacrificar bodes com frequência (...). Um altar separado é erguido pelos mecânicos de cada uma das quatro ou cinco seções da fábrica. Diversas ferramentas e outros emblemas do trabalho são colocados sobre ele (...). A fábrica e a máquina elétrica foram prontamente adotadas e receberam um lugar adequado na cerimônia religiosa. (Chakrabarty, 1989: 89-90)

Quais são as implicações da descrição feita por Chakrabarty das fábricas de sacaria de juta para uma compreensão dos espaços de trabalho? Seu relato dos rituais e das práticas de adoração no interior da fábrica pode, num certo nível, ser visto como uma das maneiras pelas quais os trabalhadores se apropriaram de um espaço estranho e o tornaram habitável. Ferramentas e máquinas foram acrescentados ao seu panteão de deuses, o mundo não familiar da fábrica foi incorporado a um mundo que lhes era familiar.

Porém, nesse relato, o espaço da fábrica não transforma os trabalhadores, as regras fabris não exercem nenhum poder sobre as vidas deles, a identidade dos camponeses não é remodelada no novo espaço que eles vêm habitar. Camponeses e artesãos carregam suas tradições com eles. Vivem num tempo que é contínuo com o passado, um tempo que é primordial. Os trabalhadores despontam como portadores de suas próprias marcas para um espaço vazio de significado.

Acredito que nós devamos ir além dessas duas noções diametralmente opostas da fábrica como um espaço. A teoria da modernização de Morris e o primordialismo de Chakrabarty não nos permitem compreender, de forma adequada, a relação dialética que os trabalhadores mantêm com os espaços que habitam e trabalham.

Num certo nível, os trabalhadores resistiram às normas e regras que buscavam moldar suas vidas, criando espaços próprios, conquistando tempos de 
sociabilidade e lazer dentro do tempo de trabalho. Em cidades como Bombaim e Kanpur, os nomes dados pelos proprietários das fábricas foram retirados e elas passaram a ser identificadas por termos que as descreviam e algumas vezes também zombavam delas. A Fábrica Star of India, em Bombaim, conhecida por seu maquinário antigo, foi rotulada de Khatara (fábrica caindo aos pedaços), e a Fábrica Union foi chamada de Bin Chimnichi Giran (fábrica sem chaminé) (Chandavarkar, 1994: 172-73). Na maioria dos centros industriais, os empregadores tiveram dificuldades em demarcar a fábrica apenas como um local de trabalho.

Os proprietários de fábricas encontraram trabalhadores lavando suas roupas e tomando banho nas dependências do estabelecimento; isso ocorria com mais frequência nas fábricas localizadas às margens dos rios. Embora as autoridades tentassem impor ordem e disciplina no interior do espaço fabril, estabelecendo controle sobre os corpos dos trabalhadores, impondo restrições sobre sua mobilidade, criando um regime de vigilância e controle, os trabalhadores desenvolveram suas próprias estratégias de negociação das regras e normas disciplinares. A parte da fábrica que abrigava as máquinas era um local de conflitos sobre mobilidade. Fronteiras eram contestadas, deslocadas e redesenhadas. Regras eram questionadas e interrupções do trabalho negociadas.

No entanto, os trabalhadores não podiam ficar inteiramente fora das normas e da ordem disciplinar que tinham de negociar. Havia, obviamente, limites no interior dos quais esses conflitos sobre as normas tinham lugar. Hierarquias de poder e privilégio no local de trabalho mediavam o resultado das negociações. Controles e conflitos gerenciais sobre mobilidade tornavam-se mais agudos durante os períodos de instabilidade. A gerência intensificava a vigilância e era mais severa a respeito da violação das normas. Para a administração, não se tratava apenas de uma questão de assegurar a continuidade da produção, mas igualmente de manter a ordem em tempos de incerteza.

A fábrica enquanto tal proporcionou um espaço para diferentes grupos trabalharem e socializarem juntos. Sabemos, com base em todos os recentes estudos do trabalho na Índia, que a sociabilidade era quase sempre restrita, que os trabalhadores quase sempre fumavam seus bidis (cigarros) e bebiam suas xícaras de chá com os amigos de sua própria comunidade, atribuindo significados comunitários ao espaço fabril. No entanto, as fronteiras da comunidade foram estendidas e redesenhadas à medida que os trabalhadores continuavam a habitar $\mathrm{e}$ a trabalhar em conjunto, no mesmo lugar. Normas de comensalidade, tabus de pureza e poluição (que evitavam que trabalhadores provenientes da casta superior jantassem junto com aqueles de castas inferiores) foram alterados e reinterpretados. Novos espaços de trabalho e sociabilidade criavam novos costumes e normas e, ao longo do processo, definiam a nova cultura da fábrica. 
O que tudo isso significa em termos do meu argumento sobre a fábrica como um espaço? Acho que nós precisamos prosseguir com a suposição de que a fábrica nunca é um espaço físico determinado e que os trabalhadores ajudam a modelar o significado que ela tem para eles. Não que os trabalhadores operem no interior de um espaço vazio e preencham-no com seu próprio significado, carregando a história de seu passado para espaços aparentemente novos. Se os trabalhadores moldaram o espaço da fábrica, eles também foram moldados no processo. Foi isso que estabeleceu a íntima relação entre os trabalhadores e a fábrica que eles valorizam frequentemente nas narrativas do passado, depois que perderam seus empregos fabris. Voltarei a esse ponto mais tarde.

\section{Espaços fora da fábrica}

Ao longo das últimas décadas, os historiadores do trabalho vêm percebendo cada vez mais a necessidade de olhar para os espaços fora do local de trabalho para compreender as experiências e as vidas dos trabalhadores. Textos recentes sobre o bairro salientam a estreita interconexão entre os diferentes espaços que os trabalhadores habitaram. Esses estudos também questionam as noções que viam a fábrica como um espaço de modernização e transformação e o bairro como um espaço de continuidade e tradição. Se a fábrica não era simplesmente um espaço no qual a modernidade revelava-se não corrompida pela tradição, o bairro também não era um espaço no qual a tradição se impunha, imutável e intacta. Eu gostaria de levar esse argumento mais longe. Meu foco consiste nos espaços de vida e lazer nos bairros da classe trabalhadora para compreender de que maneira os espaços urbanos moveram as fronteiras do velho e do novo, apagando velhas linhas ou redesenhando novas.

Tanto a hata (espécie de favela), em Kanpur, ou o chawl (cortiço), em Bombaim, reuniam um grande número de trabalhadores no interior de um espaço limitado. Uma hata típica assemelhava-se a algo como se segue:

Centenas de barracos, algumas vezes milhares deles (...) correspondendo, cada um, a um espaço de cerca de 10 pés por 8 pés. Não existem terraços ligados a esses barracos nem sistema de esgoto em todo o conjunto. Não se veem latrinas em lugar algum e os moradores fazem as suas necessidades nos campos vizinhos ou no esgoto da municipalidade.

Esses espaços de moradia, como a hata ou o chawl, não apagaram as distinções de casta e comunidade entre os migrantes que se deslocam para a cidade. 
Os espaços urbanos foram sedimentados com relações de afeto e comunidade, o que, por sua vez, estruturou os espaços de modos particulares. Religião e casta foram importantes para a organização das hatas e dos chawls. As hatas ocupadas por trabalhadores de grupos de casta superior - brâmanes e Thakurs, por exemplo tendiam a excluir os trabalhadores de castas ritualmente impuras. Em Kanpur, em ocasiões muito raras, quando acontecia de trabalhadores de castas "inferiores" conviverem com outros trabalhadores, de casta "superior", foram elaborados arranjos especiais de segregação. Os primeiros foram alocados em cômodos que abriam para a rua e não para o pátio interno. Em Bombaim, os migrantes das castas "intocáveis" foram excluídos de certos chawls e forçados a morar em barracos do lado de fora. A origem regional também se tornou um importante aspecto da paisagem da cidade industrial, com os trabalhadores migrantes da mesma região reunindo-se em torno do mesmo lugar, em um esforço para recriar laços de familiaridade.

Não se tratava, contudo, de simples continuidade. Regras de exclusão e inclusão foram continuamente redefinidas. Trabalhadores de castas ritualmente impuras (Mahars, Dheds etc.) nem sempre podiam ser mantidos fora dos chawls dominados pela casta superior. Em pensões (khanaval) localizadas nos bairros fabris de Bombaim, trabalhadores de diferentes comunidades religiosas jantavam juntos (Chandavarkar, 2004: 20).

As rígidas linhas de separação frequentemente perdiam a nitidez devido às pressões da vida urbana. Migrantes solteiros dividiam cômodos com outros provenientes da mesma região, mesmo quando não eram da mesma casta. Novas formas de socialização na cidade definiam um sentido diferente de comunidade, incorporando algumas castas e excluindo outras dos espaços compartilhados no bairro.

O papel constitutivo do espaço urbano na construção de identidades deve ser reiterado. Embora os trabalhadores lutassem para reter certas normas de pureza em suas vidas diárias, elas foram transformadas e redefinidas. A vida cotidiana dos trabalhadores no bairro era marcada por negociação, diálogo e conflito contínuos. As vidas dos trabalhadores na hata ou no chawl não estavam fechadas ao mundo exterior. Os movimentos militantes pela autoafirmação no interior do contexto urbano foram importantes para a redefinição das linhas de casta e comunidade na cidade. ${ }^{4} \mathrm{~A}$ celebração pública de festivais, procissões e movimentos religiosos criou novas unidades entre os diversos grupos de castas inferiores nas cidades. A identificação com movimentos religiosos hindus atribuiu aos grupos de casta inferiores, como os Khatiks, os Koris e os Ahirs, uma nova unidade, embora eles aprofundassem as divisões entre diferentes comunidades religiosas (Gooptu, 2000: 185-243). 
Nas áreas ao redor das hatas, nas ruas nas vizinhanças dos chawls, nas casas de chá dos bairros da classe trabalhadora, os operários tinham visibilidade. Esse foi um importante aspecto na caracterização da vida urbana em cidades como Ahmedabad, Bombaim e Kanpur. Girangaon (literalmente, aldeia da classe trabalhadora), como foi chamada, cobria uma superfície de mil acres de terra onde estavam localizadas fábricas que empregavam, no conjunto, mais de 100.000 trabalhadores. A maioria dos trabalhadores morava perto, podendo ir a pé de casa para o seu local de trabalho. Em Kanpur, as habitações da classe trabalhadora em Khalasi Lines, Gwaltoli e Parmat estavam igualmente próximas das áreas onde as fábricas estavam localizadas. ${ }^{5}$ Os bairros da classe trabalhadora em Kanpur situavam-se a uma sensível distância das Civil Lines, habitadas pela elite colonial.

Os espaços de lazer e trabalho nos bairros industriais foram importantes para a construção das identidades masculinas em casa e fora do lar. O ginásio ou a akhara, por exemplo, foi mais do que um espaço para a prática do esporte e da cultura física. Para muitos migrantes, isso também foi uma iniciação no mundo masculino da classe trabalhadora. Fisiculturistas que treinavam nas akharas (os pahalwans) adquiriam muitas vezes o status de dadas do bairro, atuando tanto como protetores quanto como predadores junto às comunidades nos embates do dia-a-dia e em tempos de crise.

Narrativas pessoais de trabalhadores que se transferiram para a cidade nas décadas de 1930 e 1940 oferecem visões instigantes do que espaços como a $a k$ hara significavam para os jovens migrantes do sexo masculino. Foi através da $a k$ hara que Shriram, que trabalhou numa fábrica de tecidos em Kanpur, por muitas décadas ganhou reconhecimento como dada (um chefe local). Sua história pessoal capta a vibração do poder que ele experimentou quando foi "coroado" o dada da área de Colonelganj. Foi quase como se ele visse a si mesmo através do olhar do bairro. Ser visto como um dada também significava a adoção de sinais mediante os quais ele podia ser reconhecido como tal.Dadas como ele tinham um estilo e uma aparência - roupas da moda, cabelos bem penteados, ar arrogante, linguagem corporal - que os distinguiam. Beber, envolver-se em brigas e se gabar disso, relembra Shriram, era então o seu passatempo favorito.

A visibilidade de Shriram no bairro também foi importante para a influência que ele exercia na fábrica e no mundo da política sindical. Na década de 1930, Shriram tornou-se um militante comunista no movimento sindical. Embora sua reputação de ser destemido fosse importante para o respeito que ele granjeara como líder sindical, as regras mediante as quais o seu poder foi legitimado pareciam diferentes. Em seu relato retrospectivo, Shriram distancia-se de seu passado como dada: parou de beber e abandonou a extravagância de seus dias de $d a d a$, adotando caminhos morais virtuosos. 
Há alguns problemas com as autorrepresentações heroicas, em que os migrantes homens parecem ter controle dos espaços que habitam. Os medos, as inseguranças, as indignidades da sobrevivência cotidiana parecem apagados. Essas histórias devem ser vistas como produtos de um tempo diferente. Num tempo de desemprego e insegurança como o de hoje, o sentimento de liberdade e de segurança que os migrantes trabalhadores experimentavam na cidade é exagerado. Essas representações, porém, também nos falam de como a vida no bairro definia a identidade dos trabalhadores, suas autoimagens, sua visão de quem eles eram e de como o mundo tinha de ser negociado. O bairro era um espaço onde as relações sociais eram moldadas e as amizades constituídas, e os conflitos e batalhas da vida social eram travados. A memória e essas negociações também modelavam o elo emocional que os trabalhadores desenvolviam com os bairros.

Hoje, os bairros tendem a ter um significado bastante diferente. Embora a indústria organizada empregasse apenas uma pequena parcela da força de trabalho em seu conjunto, mesmo nas cidades fabris, a concentração de um grande número de trabalhadores nas vizinhanças das fábricas marcou a vida nas ruas dessas áreas. Massas de pessoas caminhando, entrando em contato umas com as outras, reunidas do lado de fora dos portões das empresas na hora de mudança de turno e à noite, enchiam as ruas com um significado específico. Com o declínio das fábricas e a demissão da antiga mão-de-obra industrial, os trabalhadores passam a ver esses espaços como a corporificação da decadência e da morte. Depoimentos a respeito de Gwaltoli - um importante bairro da classe trabalhadora em Kanpur - repetem-se em relatos sobre Girangaon, em Bombaim, ou sobre Ahmedabad. Os trabalhadores dizem: "Antes, as ruas estavam repletas de pessoas à noite. Hoje, nem mesmo um pássaro gorjeia antes das seis da manhã".

\section{Repensando o rural}

A natureza da conexão entre a aldeia e a cidade é um tema recorrente nos textos sobre o trabalho na Índia. A maioria dos trabalhadores nas cidades industriais indianas não é composta de migrantes provenientes de locais distantes, mas sim de áreas rurais próximas. Em Bombaim, por exemplo, cerca de $40 \%$ dos migrantes nas primeiras décadas do século XX vieram das regiões vizinhas do Decan e Ratnagirir (Chandavarkar, 2004: 128). Em Kanpur, similarmente, quase a metade da força de trabalho era originária de distritos vizinhos (Joshi, 2003: 91-92). Em cidades industriais como Ahmedabad e Calcutá os trabalhadores também eram, em grande medida, provenientes do hinterland rural.

Como nós concebemos o rural e o urbano enquanto espaços e como encaramos o relacionamento entre eles? $\mathrm{O}$ que esses espaços representam para as 
vidas dos trabalhadores e como as atividades dos trabalhadores constituem esses espaços? Como as recentes mudanças no cenário industrial afetaram a conexão que os trabalhadores mantêm com esses espaços?

Nos textos construídos em termos da teoria da modernização, a jornada da aldeia para a cidade é descrita como uma história de progresso - da falta de liberdade/cativeiro para a liberdade, da imobilidade para a mobilidade. $\mathrm{O}$ "comprometimento" com o urbano, nesse quadro, requereu um deslocamento do rural. Certas afirmações dadas de antemão conformam a imagem do urbano moderno nesses relatos. Neles, as ambiguidades da jornada e os múltiplos significados do rural nas vidas dos migrantes na cidade não são explorados.

Nos estudos produzidos a partir dos anos 1980, as narrativas lineares de transição foram questionadas. Reconheceu-se que havia diferentes caminhos nos quais os trabalhadores na cidade retinham as conexões com a aldeia. Os fluxos humanos e materiais (de pessoas e dinheiro) entre o rural e o urbano foram importantes na construção dos laços entre a cidade e o campo. Mas como esses movimentos estruturaram a relação que os trabalhadores mantinham com os espaços que habitavam?

Para os migrantes que se deslocavam para a cidade, a aldeia era a "base" para onde retornavam, periodicamente, durante os períodos de colheita e semeadura e os tempos festivos. Trabalhar, compartilhar e se reunir com a família durante esses períodos embebiam o rural de significados específicos nas vidas dos trabalhadores. A maioria dos migrantes preferia voltar à aldeia por ocasião dos rituais de nascimento, casamento e mortes. $\mathrm{O}$ retorno ritualizado para cerimônias e festividades valorizava e santificava o rural. Para os migrantes, ele tornou-se um espaço simbólico de tradição, estabilidade e continuidade contra a falta de controle e a instabilidade do urbano. O casamento era uma instituição importante, através da qual os laços com a aldeia eram assegurados. Em cidades como Kanpur e Bombaim, a maior parte dos migrantes voltava para se casar com mulheres da aldeia. ${ }^{6}$ Mesmo mais tarde, nas décadas de 1940 e 1950, esposas e filhos de um grande número de migrantes urbanos permaneciam com suas famílias de origem na aldeia. Para muitos migrantes, o rural adquiria significado como "base" porque suas mulheres e filhos residiam ali. O acesso à terra dos ancestrais e as possibilidades de retorno para os migrantes dependiam da participação continuada de suas mulheres na produção rural.

As conexões com o rural foram reafirmadas através dos fluxos de dinheiro para a aldeia. As remessas das poupanças dos migrantes urbanos ajudavam os lares camponeses a superar temporariamente as crises e a resgatar a terra hipotecada. Por conseguinte, elas sustentavam e reproduziam uma rede de relações essenciais para a manutenção de uma "base rural". A "segurança", que aparece quase como um atributo intrínseco da conexão rural e do rural na imaginação do 
migrante foi, de fato, criada e continuamente reafirmada por meio dessas práticas. A natureza desses laços variou. Ocorreram, obviamente, diferenças entre categorias de trabalhadores, grupos de rendimentos e famílias camponesas.

Com o risco de uma simplificação exagerada, pode-se estabelecer uma ampla distinção entre três categorias. A primeira compreende aqueles migrantes que se transferiram para as cidades cortando os laços com suas aldeias. $\mathrm{O}$ estudo de Breman sobre os operários têxteis em Ahmedabad mostra como a maioria dos migrantes estabeleceu-se na cidade rompendo suas conexões com suas aldeias. Ao contrário de outras cidades, os trabalhadores em Ahmedabad não realizavam viagens de volta à aldeia ou enviavam dinheiro para suas famílias. ${ }^{7}$ A segunda diz respeito aos trabalhadores que mantinham empregos ocasionais e moviam-se circularmente entre o campo e a cidade. $\mathrm{O}$ deslocamento dos trabalhadores portuários e da construção civil em Bombaim, por exemplo, foi regulado pelas chuvas das monções, que interrompiam o trabalho por longos períodos (Chandavarkar, 1994: 114). Trabalhadores empregados em pequenas indústrias e no setor informal em Gujarat eram "livres" e estavam constantemente se deslocando (Breman, 1998). A terceira categoria abrange aqueles trabalhadores empregados em atividades regulares que passavam períodos mais longos na cidade, pontilhados por viagens curtas à aldeia. No final dos anos 1920, quando houve uma pesada retração no setor têxtil e em outras indústrias em Bombaim, um grande número de trabalhadores deixou a cidade e regressou às suas aldeias.

Com a queda dos ganhos na cidade, o rural adquiriu um significado renovado para os migrantes trabalhadores. Para o pobre rural que havia migrado para a cidade anteriormente, os empregos fabris ajudavam a saldar dívidas e a livrar seu pedaço de terra das hipotecas. Hoje, a relação se inverteu e a propriedade na aldeia confere a segurança que, de uma forma diferente, os empregos fabris davam no passado. Trabalhadores como Ramcharan, que manteve uma estreita conexão rural, relembram com saudade do valor dos seus ganhos nos empregos fabris no passado. Nos velhos tempos, conta ele, os trabalhadores recebiam seus pagamentos em moedas de prata. Foi economizando essas moedas que ele pôde comprar seis acres e meio de terra na aldeia. Embora o valor monetário das moedas não fosse grande, seu valor real, quando investido em terra, parecia incomparavelmente maior. Para Ramcharan, o valor incremental embutido nas moedas de prata era realizado no aumento fenomenal no valor da terra. A terra que ele havia comprado por 500 rúpias valia agora, nos anos $1990,80.000$ rúpias. ${ }^{8}$

No contexto atual de falta de trabalho e incerteza, a segurança proporcionada pelos empregos na fábrica tende a ser supervalorizada e a analogia entre a terra e os empregos urbanos, superenfatizada. Os empregos fabris são representados, em muitas narrativas de trabalhadores, como uma herança a ser passada 
geração a geração. Essa herança assegurava uma continuidade geracional e a reprodução de habilidades, que era a base da identidade do trabalhador e que podia se tornar a fonte de ganhos estáveis para toda uma família. O fechamento das fábricas, como, por conseguinte, muitos argumentam, lança no desemprego não apenas a presente geração, mas também as futuras gerações. ${ }^{9}$

Nos anos 1990, quando as grandes fábricas estavam cerrando as portas e o trabalho industrial nas cidades era escasso, representações nostálgicas atribuíam ao trabalho urbano o tipo de segurança que o trabalho rural e a terra tiveram para eles no passado. Diante da ausência de trabalho na década de 1990, o emprego fabril dos velhos tempos parecia análogo à terra: uma herança que podia ser passada para as futuras gerações. Trabalhadores como Ramcharan, ao olharem para trás, consideravam o emprego que tinham numa fábrica de tecidos em termos do valor incremental da terra que haviam comprado com suas economias.

Como o fim das indústrias tradicionais e a marginalização do trabalho, temas que eu venho discutindo, transformaram a natureza do espaço político nas cidades industriais? Essa questão está ganhando uma importância crescente nesses tempos de desregulamentação na Índia. Vou tocar nesse ponto sucintamente.

\section{Trabalho marginalizado e erosão do espaço político}

As primeiras duas décadas após a independência foram caracterizadas pela visibilidade do trabalho na esfera pública, pela afirmação coletiva dos direitos dos trabalhadores como cidadãos e pelo reconhecimento da significação dos eleitores da classe trabalhadora pelos partidos políticos. Hoje, o reverso dessas tendências parece aparente. $\mathrm{O}$ trabalho tornou-se cada vez mais invisível na esfera pública, a existência coletiva dos trabalhadores como classe é questionada, e há um declínio da presença da classe trabalhadora na arena política. Como os trabalhadores experimentam esse processo de marginalização e de virtual não reconhecimento de suas demandas a uma cidadania ativa?

O fechamento das fábricas nos centros da indústria manufatureira tradicional representou mais do que uma perda econômica para os trabalhadores; significou, também, a morte da cultura política nas cidades industriais. As redes sociais na cidade, como já coloquei, não foram apenas uma continuação dos laços comunitários ou de parentesco do passado, mas também um elemento formador ativo do contexto urbano. Necessidades materiais no interior da cidade, a necessidade de moradia e crédito, a celebração de festivais e as atividades no tempo de lazer contribuíram para a criação de novas relações e novas noções de comunidade e identidade. Não se pretende pintar um quadro romantizado de tradições de 
solidariedade. Os bairros, como já vimos, foram também espaços de conflito e espaços nos quais os goondas (valentões) aterrorizavam os migrantes recém-chegados à cidade e nos quais as questões envolvendo a honra da comunidade podiam se tornar a base de terríveis violências entre diferentes grupos sociais. $\mathrm{O}$ ponto que eu elaboro a seguir é que a possibilidade, no passado, da existência de vários espaços para a solidariedade na cidade está sendo agora rapidamente erodida. ${ }^{10}$

A mudança da situação em velhos centros industriais como Kanpur é aparente na vida das ruas de áreas como Gwaltoli, em que estavam localizados alguns dos primeiros estabelecimentos têxteis e agrupamentos da classe trabalhadora. Gwaltoli chegou a ser conhecida popularmente como a fortaleza dos trabalhadores (mazduron ka garh). Foi lá que algumas das primeiras greves irromperam e que manifestações e meetings foram organizados. E em certos momentos da luta dos trabalhadores, eles literalmente ganharam o espaço da cidade, reordenando suas regras e paralisando o funcionamento normal dos governos.

Os anos do pós-guerra e do entre-guerras foram marcados na Índia por muitos momentos de tumulto, quando as populações trabalhadoras nos centros industriais afirmaram sua presença no espaço público e desafiaram as instituições que mantinham a ordem. Em Kanpur, por exemplo, ocorreu uma greve geral em julho-agosto de 1938 que durou 52 dias, envolvendo mais de 46.000 operários. A greve foi apoiada por trabalhadores de quase todas as indústrias na cidade - fábricas de tecidos, curtumes, moinhos de trigo, fábricas de fósforos, fundições de ferro. Nesses dias, Kanpur foi literalmente tomada pelos trabalhadores. As fábricas foram fechadas, as ruas foram ocupadas pelos operários e as estruturas regulares das autoridades de governo entraram em colapso. No discurso popular, a cidade veio a ser conhecida como lal Kanpur, literalmente a "cidade vermelha", e isso veio a fazer parte da memória coletiva durante muitas décadas.

O pânico dos funcionários públicos e as preocupações dos industriais da época são vigorosamente captados em algumas caricaturas e ilustrações publicadas nos jornais. Elas mostram como as autoridades procuravam ordenar os espaços e como reagiam quando as atividades dos trabalhadores abalavam essa noção de ordem espacial.

Numa dessas caricaturas, publicada durante a greve de 1938, um piqueteiro é mostrado sendo arrastado pela rua numa charpoy (um tipo de cama portátil feita de corda), enquanto um policial, de expressão cansada, em pé diante dele, tenta organizar o tráfego. Numa outra imagem, aparecem cópias de autorizações/passes emitidos pelo sindicato local para permitir que os seus portadores entrem nas dependências da fábrica. Os passes são selados e assinados pelo sindicato local. Na terceira imagem, uma multidão de grevistas, grandes e fortes, alguns carregando bastões (lathis), cercam a pequena e frágil figura de um líder do Congresso que se opunha à greve. 
Em todas essas imagens - e elas são muito numerosas - ficamos diante daquilo que as atividades dos trabalhadores significavam para as autoridades e do modo como as ideias de espaço foram redesenhadas em tempos em que o confronto chegava ao clímax. As autoridades típicas - os policiais, os guardas, os políticos - são representadas, todas elas, desprovidas de poder. A ordem normal da rua, da fábrica e do bairro foi quebrada e o caos parece reinar, enquanto os trabalhadores afirmam seu direito sobre o espaço. A noção de que governo significa o ordenamento de espaços é reforçada nos cartuns pela projeção do nervosismo dos espaços desordenados, nervosismo que reconhece a maneira pela qual os trabalhadores se apropriam dos espaços e os reconstituem nesses momentos.

Trabalhadores entrevistados na década de 1980 recordaram os tempos vividos no passado, quando era impossível caminhar sem esbarrar em outros trabalhadores - milhares deles andavam pelas ruas de Gwaltoli nos horários da mudança de turno nas fábricas. A vida ao redor das casas de chá, das barracas que vendiam tabaco, os ambulantes do lado de fora dos portões das fábricas, era uma vida que alimentava as associações políticas e as solidariedades. Era ali que os trabalhadores se reuniam, antes e durante as greves, para trocar informações a respeito dos salários pagos e das condições de trabalho; era ali que eles refletiam sobre como poderiam enfrentar as estratégias dos patrões. Era por meio dessas conversas que a classe trabalhadora veio a se tornar um ator público, que afirmava sua presença dentro do espaço urbano, social e político. São esses espaços que estão sendo agora removidos e suprimidos como parte do desenvolvimento urbano nas áreas metropolitanas.

O mundo da política sindical radical, do modo que foi construído anteriormente nas cidades industriais, reafirmava, e não contestava, a natureza masculinizada da esfera pública na cidade. $O$ ingresso no mundo da política sindical era valorizado pelos jovens trabalhadores. O reconhecimento como líderes, mesmo no nível da fábrica e no nível de seção fabril, conferia-lhes um novo senso de identidade. Muitos trabalhadores, que viveram no passado a experiência de militantes do movimento sindical, relembram que quando eram jovens sempre sonhavam em se tornar líderes. Havia uma clara conexão entre o mundo dos ativistas sindicais e dos valentões dos bairros nas cidades industriais. Para adquirir um senso de poder e controle na cidade, quer como líder sindical quer como um dada local, era necessária uma masculinidade agressiva. Mesmo os líderes de menor expressão, que atuavam nas seções das fábricas, eram caras duros, que podiam mostrar-se arrogantes e intimidar outros trabalhadores. A exemplo dos dadas locais, que se gabavam de suas façanhas contra os valentões no bairro, os líderes sindicais vangloriavam-se de se vingar dos "fura-greves". Muitos trabalhadores que adquiriram reconhecimento como líderes sindicais foram conhecidos e temidos, anteriormente, como dadas de bairro. Os dirigentes sindicais foram, mui- 
tas vezes, ambivalentes a respeito dessas associações quando se referiram ao seu passado, distanciando-se delas. Ao contrário dos dadas, que ostentavam sua capacidade de consumo, os sindicalistas identificavam-se com o legado dos dias do nacionalismo e buscavam legitimidade através da defesa dos valores de austeridade e renúncia de Mahatma Gandhi.

Hoje, os espaços em torno dos quais os trabalhadores construíram suas noções de solidariedade e de identidade nos antigos centros manufatureiros estão reduzidos. Não somente os locais de trabalho e moradia vêm sendo afetados por processos de reestruturação e declínio econômicos, como também os espaços das associações sociais e políticas foram gradualmente se desintegrando. De fato, como muitos estudos demonstram, o objeto das estratégias do empregador no presente é marginalizar o trabalho do espaço político.

As experiências de perda e fragmentação no presente remodelam os caminhos nos quais as memórias são apropriadas. Anteriormente, os trabalhadores manifestavam um sentimento de orgulho ao narrar histórias das greves e das lutas ocorridas no passado; hoje, há uma relutância em falar sobre as lutas coletivas, um distanciamento consciente do passado. Qualquer discussão a respeito das lutas dos trabalhadores parece quase anacrônica e sem sentido se vista do presente.

Ao examinar a questão da marginalização do trabalho da esfera pública, temos de distinguir entre as diferentes fases na relação entre o Estado, o trabalho e o capital. ${ }^{11}$ A primeira década após a independência foi um período em que o Estado pós-colonial desempenhou um papel ativamente intervencionista, tanto através do investimento em empresas públicas quanto da tentativa de regular os salários e as condições de trabalho. O Estado tentou encorajar o que é caracterizado como sindicalismo "responsável" e projetou-se como um árbitro legítimo dos interesses do trabalho. Através do movimento nacional, a All-India Trade Union Congress (AITUC) despontou como uma organização guarda-chuva, que representava o espectro das opiniões políticas.

A partir de meados dos anos 1960, o declínio no investimento público e a estagnação industrial afetaram o emprego e os salários. Os trabalhadores protestaram de formas novas e militantes, e o número de greves e de dias de trabalho perdidos disparou - triplicou entre 1965 e 1973 - criando, em algumas regióes, uma crise de capital e forçando uma fuga de capitais das regiões de sindicalismo militante para os novos centros industriais. A política de Estado oscilou entre medidas populistas (mobilização em torno de slogans como garibi hatao (remover a pobreza) e uma legislação repressiva contra as greves durante o estado de emergência. Contudo, em contraste com o presente, quando as sanções do Estado permitem que os gerentes adotem estratégias de trabalho flexíveis, nos anos 1970, o regime do Partido do Congresso aprovou uma emenda à Lei das Disputas Indus- 
triais que tornava obrigatório para as firmas que empregassem mais de 300 trabalhadores obter a permissão do governo antes de dispensar seus empregados.

O final da década de 1970 e o início da década seguinte foram marcados por dois processos contraditórios. Em primeiro lugar, houve o crescimento de poderosos sindicatos no nível de fábrica, não filiados a partidos políticos; e, em segundo lugar, houve um declínio da força dos sindicatos mais tradicionais. Os novos sindicatos podiam organizar as greves nas indústrias mais novas e mais lucrativas, enquanto os sindicatos mais antigos, associados ao setor manufatureiro tradicional, entravam em declínio. Para lidar com o sindicalismo militante, muitas companhias começaram a lançar mão da terceirização e do "enxugamento" da folha de pagamento, um fenômeno que se tornou parte integrante da paisagem industrial na Índia de hoje. Mesmo antes da fase atual de desregulamentação, o Estado foi abrindo mão do seu papel intervencionista, recuando, enquanto as gerências esmagavam as organizações de trabalhadores, direta ou indiretamente, mediante a informalização do trabalho no setor "formal". Foi também nesse período que a crescente influência das ideias neoliberais thatcherianas de autoajuda legitimou o ataque aos setores "não lucrativos". Slogans populistas desapareceram gradualmente e a retórica do bem-estar entrou em declínio.

Esses processos alimentaram as tendências presentes no atual momento. Vivemos agora um tempo de liberalização, de programas de reestruturação econômica patrocinados pelo Fundo Monetário Internacional (FMI). Hoje, mesmo os fortes e independentes sindicatos da década anterior não detêm mais uma posição de força. Processos de subcontratação, enxugamento e terceirização estão afetando todos os setores, tornando difícil para as organizações no nível de fábrica resistir às políticas gerenciais. Assistimos a um processo de desindustrialização, de dissolução da classe trabalhadora tradicional e de completa ruptura de velhas formas de sindicalismo. O número de greves declinou ao longo desse período, e o de dias-força de trabalho perdidos por conta das greves despencou. ${ }^{12}$ A Segunda Comissão Nacional de Trabalho estabelecida em 1999 flexibilizou a legislação sobre contratos de trabalho, permitindo que as gerências expandissem o setor informal e colocassem sob ameaça permanente a força de trabalho sindicalizada. As mudanças posteriores na Lei sobre Disputas Industriais tornaram as greves espontâneas difíceis e os lockouts fáceis. O Plano de Aposentadoria Voluntária (Voluntary Retirements Scheme - VRS) permite aos gerentes deslocar trabalhadores sindicalizados, reduzir a força de trabalho e terceirizar a produção. O que é mais doloroso nos dias de hoje é a crescente legitimidade que essas ideias vêm adquirindo. Para os economistas neoliberais e os elaboradores de políticas, essas tendências parecem quase naturais e inevitáveis. Para o público alimentado no discurso da desregulamentação, a preocupação com os direitos e com o bem-estar dos trabalhadores parece um remanescente do passado. 
Levantar questões relativas ao trabalho - questões de deslocamento, de emprego alternativo para trabalhadores marginalizados - parece algo impraticável e fora da realidade. Nesse cenário, pode-se quase ver a morte do eleitorado da classe trabalhadora na arena política. Enquanto no passado todos os partidos e líderes políticos procuravam chegar aos trabalhadores industriais, e os seus principais líderes em nível nacional foram eleitos com base no voto da classe trabalhadora, hoje a ideia de um voto da classe trabalhadora parece anacrônica. Entre os eleitores da velha classe trabalhadora, a linguagem de classe na arena pública vem sendo cada vez mais deslocada por uma linguagem de religião e casta.

As organizações operárias que articulavam a voz coletiva do trabalho estão em um estado de declínio. O sindicalismo tradicional na Índia, construído com base em um otimismo a respeito da expansão da indústria fabril, está em crise. As suposições sobre as quais o sindicalismo se assentava estão ameaçadas. As antigas organizações e seus líderes encontram-se desacreditados por não terem obstruído a maré de fechamento das fábricas e as reformas neoliberais. As organizações independentes no nível de fábrica enfrentam a possibilidade de um colapso total em vista do fato de as estratégias de enxugamento e terceirização da produção estarem se tornando uma norma.

A transformação dos espaços de trabalho e a dizimação da velha classe trabalhadora industrial significaram um gradual deslocamento do trabalho do discurso público. E isso significou uma crescente invisibilização do trabalho dos espaços públicos.

\section{Espaços remodelados quanto ao gênero}

As mudanças sobre as quais vimos falando também representaram uma remodelação dos espaços de trabalho no que concerne ao gênero.

Hoje, as narrativas dos trabalhadores homens na maioria dos centros industriais jogam com imagens de decadência e envelhecimento, elaborando comparações entre seus corpos decrépitos e as máquinas desgastadas na fábrica. É como se o trabalho atribuísse fisicamente força, e o não-trabalho criasse uma sensação de fraqueza, uma redução dos ritmos do corpo. Nas narrativas dos trabalhadores dos anos 1990, há um distanciamento das labutas e da dureza do trabalho no passado. O trabalho na fábrica é celebrado como enriquecedor e recompensador. Há um sentido de união com as máquinas e com os estabelecimentos onde eles trabalhavam. Muitos operários afirmavam orgulhosamente que os teares nunca paravam em suas fábricas. A estreita disciplina no interior da qual eles quase sempre tiveram de trabalhar no passado é recontada por muitos com um sentido de realização individual e orgulho masculino. ${ }^{13}$ 
Para aqueles na folha de pagamento da fábrica, a rotina diária por muitos anos era conversar no portão da fábrica nas horas de mudança de turno. Homens sentados em círculo contavam as novidades e depois, resignadamente, seguiam seu caminho para casa. A cada dois ou três meses, os trabalhadores estavam envolvidos em alguma ação - um sit-in ou uma manifestação para exigir seus salários -, para depois as esperanças serem novamente perdidas. Para muitos, porém, estar na folha de pagamento e a ficção do trabalho era algo importante. Aceitar o Plano de Aposentadoria Voluntária e se aposentar significaria o selo do desemprego, que, para um homem, era uma marca de humilhação.

Como os trabalhadores negociam suas vidas em um mercado de trabalho em retração? Elaborar estratégias de sobrevivência envolve a descoberta de caminhos que ofereçam alguma proteção econômica e preservem um sentido de si mesmo e a dignidade. Que modalidades de estratégias os trabalhadores vislumbram nesse contexto?

Os trabalhadores que já entraram na casa dos 50 anos parecem os mais atingidos. Depois de uma década de espera pela reabertura das fábricas, eles experimentam uma sensação de cansaço e inércia. Muitos que trabalharam como tecelões nas fábricas por mais de 30 anos parecem curvados pela idade e pelos caprichos do tempo. Não apenas é difícil encontrar trabalho, como eles também sentem que nunca mais terão a mesma satisfação. ${ }^{14}$ As famílias em que os homens haviam trabalhado como tecelões podiam sobreviver no passado com os ganhos de apenas um membro masculino. Os signos de seu status e dignidade no passado hoje estão perdidos. Eles dependem em grande parte dos rendimentos das mulheres e filhos. Ser um berozgar (desempregado) é uma situação com a qual os trabalhadores homens acham difícil lidar. Não ir ao trabalho significa uma diminuição da presença patriarcal no lar. Em casa, eles se escondem em um canto, evitando os visitantes. Sua linguagem corporal, o olhar desesperançado, os óculos de lentes grossas depois de anos de trabalho tecendo, muitas vezes tendem a marcá-los e os tornam reconhecíveis como ex-operários fabris.

Os homens desempregados perambulam com bastis ehatas, sem ter nada para fazer. Noções de mudança de tempo quando o lazer é ilimitado: horas e dias são passados em casa ou no gali (beco) do lado de fora. Mesmo na vida em família, as mulheres tendem a ter um regime diferente de tempo. Há o horário das refeições e os tempos definidos para quando a água deve ser buscada ou os vegetais e as provisões domésticas comprados. Muitas mulheres eram abertamente críticas dos homens ociosos, que não se banham e que dormem até o meio-dia. ${ }^{15} \mathrm{Algu}-$ mas delas se sentiam bastante à vontade para fazer pouco dos homens que ficam sentados em círculos, jogando e fazendo fofoca no recinto da hata. A perda do trabalho para os homens implica muito mais do que uma perda econômica. Signifi- 
ca também uma desestabilização da autoridade no interior da família e a perda de respeito na vizinhança. Os homens que não estão ocupados de modo útil tornam-se objeto de risos das mulheres. ${ }^{16}$

Outros que sempre fizeram parte da força de trabalho informal adotam uma atitude de resignação. Sua rotina é fixa. Eles vão para o mercado dos peões em Moolganj todas as manhãs, e ficam esperando ser contratados. Se não aparece trabalho até o meio-dia, voltam para casa. Algumas vezes, o ritual prolonga-se por dias seguidos, sem oferta de trabalho. É esse o padrão para trabalhadores ocasionais, como Durga Prasad, que trabalha na cidade de Kanpur há 30 anos. Às vezes passam-se quatro ou cinco dias sem trabalho algum para ele. ${ }^{17} \mathrm{E}$ quando aparece trabalho, ganha 40 rúpias no final do dia.

As vidas dos pequenos comerciantes dos bazares nos bairros da classe trabalhadora foram sempre interligadas às dos operários fabris da cidade. Muitos deles continuam com seus velhos comércios, mas as suas condições de trabalho não são mais as mesmas. Os vendedores de vegetais andam sem destino, procurando compradores para os seus produtos gastos e sem atrativos. Com o pouco dinheiro que eles obtêm de volta, mal têm condições de comprar mais produtos para formar estoque. Alguns vendem gêneros comestíveis - como grão-de-bico cozido e puris $^{18}$ - e conseguem encher um carrinho alguns dias por semana. Mesmo os pequenos lojistas que vendem calçados - sapatos e chinelos das marcas mais baratas - sentem a diferença. Descrevendo seus apertos atuais e como as fábricas afetavam sua vida no passado, Abdul Parvez, um pequeno comerciante de sapatos, faz um discurso curto. Lançando mão de gestos dramáticos e metáforas corporais, Abdul recita: "A fábrica da Elgin era as minhas mãos, a central elétrica o meu estômago, a fábrica da Muir meus olhos, eu podia vê-las e senti-las cheias e contentes". Ele repetia isso duas vezes para causar efeito. ${ }^{19}$ Para pequenos comerciantes como ele, instalados no antigo núcleo da atividade da classe trabalhadora - Gwaltoli -, as fábricas sustentavam diferentes ocupações na cidade. ${ }^{20}$ Agora, tudo parecia perdido.

As experiências dos trabalhadores na fase atual de "desindustrialização" são também mediadas por equações de gênero no interior da família e de seu background de casta. Em um mercado de trabalho no qual os empregos para os homens são cada vez mais escassos, os ganhos das mulheres estão se tornando cada vez mais importantes enquanto estratégia de sobrevivência. $\mathrm{O}$ trabalho das mulheres representa uma ameaça para as estruturas patriarcais entrincheiradas, e observa-se uma resistência continuada a ela. Contudo, as estratégias de negociação variam nos diferentes tipos de lares de trabalhadores.

Nos lares de trabalhadores da casta superior, o trabalho assalariado para as mulheres sempre foi visto como uma violação da honra da família. No 
contexto atual de declínio acelerado da renda familiar, eles lutam para sobreviver, mas continuam a segregar a mulher, resistindo à sua entrada nos espaços públicos e buscando preservar, desesperadamente, as equações existentes de gênero no interior das famílias. Porém, a presença patriarcal, em casa, do provedor homem, parcialmente empregado ou desempregado, vem diminuindo. Com o declínio do macho provedor, o trabalho das mulheres adquiriu um significado crescente dentro da economia doméstica. ${ }^{21}$ Em muitos lares da classe trabalhadora das castas inferiores, o preconceito contra o trabalho feminino não ia tão longe. ${ }^{22}$ Todavia, o emprego fabril garantido para muitas gerações de homens e uma situação econômica melhor levaram a uma gradual retirada das mulheres do trabalho assalariado, sendo a segregação das mulheres vista como necessária para justificar as reivindicações por um status mais elevado. Porém, numa situação de declínio da renda dos homens, as mulheres, em muitos desses lares, estão agora engajadas em atividade assalariada dentro de casa. Ram Pyari, que ganha a vida fazendo bidis em Kanpur, ressalta o fato de que no passado, quando os homens em seu lar familiar tinham empregos fabris, as mulheres não trabalhavam. ${ }^{23}$ Algumas mulheres que foram trabalhar tentaram manter o seu trabalho em sigilo dos vizinhos. ${ }^{24}$

Nas famílias em que as mulheres são agora os membros que contribuem financeiramente de forma regular e os homens têm ocupações ocasionais, as relações de poder em casa são frequentemente pesadas. Nessas famílias, os homens sentem uma dupla perda: a perda do emprego e a perda da autoridade masculina em casa. No entanto, os homens lutam para manter o sentido de si mesmos. Um grande número deles continuou a definir sua masculinidade através da bebida e da sua associação com os lugares para homens que a vendem. ${ }^{25}$ Pesquisas sobre o orçamento familiar sugerem que os gastos com bebida nos lares da casta inferior eram mais elevados do que em outras castas. ${ }^{26}$ Os funcionários públicos que efetuaram essas pesquisas duvidam da confiabilidade desses cálculos, uma vez que as castas inferiores tendem a exagerar suas despesas com bebida. Os varredores que trabalham na cidade, por exemplo, consideravam um gasto mais elevado com bebida como sinal de status. O consumo de álcool num contexto em que os rendimentos dos homens são decrescentes envolvia controvérsias sobre recursos e conflitos domésticos entre a noção feminina de parcimônia e a prodigalidade masculina. Muitas mulheres afirmaram que os homens tinham de ser responsáveis pelas suas próprias despesas com bebida. ${ }^{27}$ Era comum em muitas famílias que os homens gastassem o que ganhavam durante o dia com bebida, enquanto as mulheres eram as provedoras dos filhos. A imprevidência diante da adversidade era, para eles, uma afirmação do orgulho masculino. ${ }^{28} \mathrm{~A}$ autoafirmação masculina também ganhou a forma de uma agressão ampliada em casa. Os sentimentos de castração e de orgulho perdido são temporariamente superados atra- 
vés de demonstrações de poder físico sobre as mulheres. Em muitos lares da casta inferior, as mulheres estavam quase resignadas à ideia de serem espancadas à noite por seus homens bêbados. A cruel realidade da vida cotidiana estruturou, em última instância, as relações de poder nos lares. Isso não significa esboçar qualquer conexão necessária entre sentimentos de castração e violência contra as mulheres. Entretanto, acredito que o mundo doméstico tornou-se um domínio mais conflituoso quando os espaços para a afirmação da individualidade masculina que existiam anteriormente foram deslocados. Os padrões estabelecidos de agressão masculina são intensificados numa situação em que a própria identidade do homem está colocada em questão.

O declínio das indústrias tradicionais e a expansão do "setor informal" no contexto atual apresentam, pois, profundas implicações culturais. A erosão dos espaços em torno dos quais a cultura do trabalho e do lazer foi construída originou uma crise das identidades masculinas. A invisibilidade dos homens na força de trabalho atinge o espaço interno do mundo doméstico, ameaçando a autoridade dos homens nos lares, deslocando as equações de gênero. Dentro desse cenário, movimentos que se mobilizam em torno de políticas de violência e de ódio comunal estão ganhando terreno, destruindo as tradições de solidariedade e coletividade da classe trabalhadora construídas no passado.

\section{Conclusão}

O que nós assistimos hoje é a uma profunda alteração nos espaços do trabalho. Com o declínio da indústria fabril tradicional, o local do trabalho mudou, sendo muitas vezes levado para o interior do espaço doméstico, nas vielas das cidades. O esforço para marginalizar o trabalho da esfera pública, do espaço político, é acompanhado do esforço para deslocar a classe trabalhadora dos bairros operários nas áreas urbanas. Autores como Nair e Chatterjee mostraram recentemente como as cidades na Índia estão sendo "limpas", transformadas em espaços ordenados, livres da presença "perturbadora" das favelas e dos pobres. Esse esforço para transformar o espaço urbano atinge os espaços aos quais a classe trabalhadora teve direito no passado.

Nesse contexto, creio que devemos entender os novos espaços que o trabalho venha a ocupar, mas devemos também retornar àqueles espaços que foram, anteriormente, importantes para os trabalhadores. Devemos acompanhar os processos através dos quais esses espaços foram alterados e repensar o significado que esses espaços tinham nas vidas dos trabalhadores. 
1. Ver, por exemplo, Breman (2002), Bhowmik e More (2002), Vanamala (2001), Noronha e Sharma (1999).

2. Sobre a crise na indústria têxtil, ver Chandrashekhar (1984), Goswami (1990) e Roy (1998).

3. A força de trabalho total era superior a 750.000 nos anos 1980 . Cerca de $75 \%$ estavam ocupados no setor informal (Breman, 2004: 143, 145).

4. Ver também, a esse respeito, Gooptu (2000).

5. Descrições semelhantes são numerosas para Calcutá e Ahmedabad. Em Calcutá, os migrantes viviam em barracos ao redor das áreas fabris. Em um bolsão em torno de Kankinara, Jagatdal, Bhatpara e Naihati, aproximadamente 85.000 pessoas viviam amontoadas numa área diminuta de 5,5 milhas quadradas (Goswami, 1990: 90). Sobre Ahmedabad, ver Breman (2004: 31-36).

6. A amostragem de Niehoff revela que $76 \%$ dos casamentos foram contraídos na aldeia (Niehoff, 1959: 81).

7. Breman (2004: 16-17) mostra que na virada do século a maioria dos trabalhadores na cidade de Ahmedabad não tinha conexão alguma com suas aldeias.

8. Entrevista com Ramcharan, que trabalhou na Fábrica Muir desde meados da década de 1940.

9. Entrevista com Shriram Sharma, Elgin 2.

10. Para uma discussão do bairro em Bombaim, ver Chandavarkar (1994), Patel e Thorner (1995) e Sharma (2000). Sobre Ahmedabad, ver Breman (2003 e 2004).
11. Sobre a distinção entre as diferentes fases, ver também o trabalho de Bhattacharjee (1999).

12. Comparado às 2.245 greves em 1982, houve apenas 773 greves em 1995, um declínio de $65 \%$, e o número de dias de trabalho perdidos diminuiu em cerca de $80 \%$ no mesmo período, de 21.208 .000 a 5.720 .000 .

13. Entrevistas com Pramod Awasthi e Muhammad Said, Elgin Mills. Ramcharan, por exemplo, referiu-se com orgulho aos tempos em que eles, os trabalhadores, não tinham permissão para ir ao banheiro durante a jornada de trabalho.

14. Entrevista com Niamat Rasul, Elgin Mills 2.

15. Sameena, mulher que está na casa dos 50 anos e que mora com o filho desempregado, conta que ele nunca acorda antes das 11 horas ou do meio-dia. "É humano dormir a metade do dia?", ela pergunta. Entrevista com Sameena, Fazalganj, Kanpur.

16. Entrevistas com Shyama e Krishna, Mathiya Vala Hatha, Kanpur.

17. Entrevista com Durga Prasad, Cooperganj, Kanpur.

18. Puri é uma espécie de pão frito no azeite. Entrevista com Hasan Ahmad, Maqbara, Kanpur.

19. Entrevista com Abdul Parvez, Gwaltoli, Kanpur.

20. Gwaltoli era uma área que abrigava algumas das mais importantes fábricas e era também o centro onde as greves mais relevantes começaram.

21. Para uma elaboração desse argumento, ver Joshi (no prelo). 
22. Essas incluem castas como os Koris e os Chamars Koris, tradicionalmente ligados à tecelagem. Muitas mulheres de extração Kori estavam envolvidas em ocupações como a feitura e a costura de bidis. Os Chamars, tradicionalmente, trabalhavam com couro.

23. "Meu sogro trabalhava numa fábrica e por isso minha sogra não trabalhava". Entrevista com Ram Pyari, Chuna Bhatiya, Kanpur.

24. Entrevista com Asha, que trabalhou numa pequena unidade fabricante de hardware, Afim ki Kothi, Kanpur.

25. Um estudo dos anos 1960 revela que o consumo de bebida alcoólica era mais comum em cidades industriais como Kanpur. Cerca de 70\% dos trabalhadores em Kanpur eram classificados como "pessoas que bebiam ocasionalmente", ao passo que $30-50 \%$ eram considerados "pessoas que bebiam com regularidade", aquelas que gastavam em média $20-25 \%$ dos seus salários com bebida, percentual que chegava a $50 \%$ no caso dos homens solteiros. Report of the Study Team on Prohibition (1964, vol. 2: 227).

26. Eram consideradas "pessoas que bebiam com regularidade" aquelas que gastavam em média $20-25 \%$ dos seus salários com bebida, percentual que

Referências bibliográficas

BHATTACHARJEE, Debashish. 1999. Organised Labour and Economic Liberalisation India: Past, Present and Future. ILO discussion paper, 105.

BHOWMIK, Sharit; MORE, Nitin. 2002. Ex-Textile Mill Workers in Central chegava a $50 \%$ no caso dos homens solteiros. De acordo com um levantamento efetuado na década de 1930, o gasto com bebida entre os varredores "intocáveis" era maior do que entre os membros das outras castas. Os pesquisadores observaram o seguinte: "Quando começamos a nossa pesquisa, constatamos que a maioria dos varredores tinha orgulho da quantia que gastavam com substâncias tóxicas; eles consideravam essa quantia uma espécie de indicador do seu status social". Report of the Harijan Survey Committee 1933-34, Kanpur (1934: 30).

27. Entrevista com Shyama, Lachmipurwa. Ver também Sunita, Tijiya e Rajkumari, Bisati ka hata. Essa última área foi habitada, em grande medida, por famílias da casta "intocável" dos Kureel. Os homens Kureel dessa localidade trabalhavam anteriormente em estabelecimentos de couro e agora estão desempregados.

28. Mulheres de muitas famílias da casta inferior consideravam inútil pedir dinheiro aos homens para as despesas da casa. Sunita ironiza: "Se nós nos queixamos e dizemos que é difícil lidar com essa situação, os homens nos dizem para arranjar outro". Entrevista com Sunita, Bisati ka hata.

Mumbai. Economic and Political Weekly, 36:52, dezembro-janeiro.

BREMAN, Jan. 1998. Footloose Labour: Working in India's Informal Economy. Cambridge: Cambridge University Press. 
. 2002. An Informalised Labour System: End of Labour Market Dualism. Economic and Political Weekly, 36:52, dezembro-janeiro. 2003. The Labouring Poor in India: Patterns of Exploitation, Subordination and Exclusion. Nova Delhi. 2004. The Making and Unmaking of an Industrial Working Class: Sliding Down the Labour Hierarchy in Ahmedabad. Nova Delhi.

CHAKRABARTY, Dipesh. 1989. Rethinking Working-Class History: Bengal 1890-1940. Delhi.

CHANDAVARKAR, Raj. 1994. The Origins of Industrial Capitalism in India: Business Strategies and the Working Classes in Bombay, 1900-1940. Cambridge, Cambridge University Press. 2004. From Neighbourhood to Nation: The Rise and the Fall of the Left in Bombay's Girangaon in the Twentieth Century. In: MENON, Meena; ADARKAR, Neera. One Hundred Years, One Hundred Voices. The Mill Workers of Girangaon: An Oral History. Calcutá: Seagull.

CHANDRASHEKHAR, C.P. 1984. Growth and Technical Change in Indian Cotton-Mill Industry. Economic and Political Weekly, 19:4.

GOOPTU, Nandini. 2000. The Politics of the Urban Poor in Early Twentieth-Century India. Cambridge: Cambridge University Press.

GOSWAMI, Omkar .1990a. Sickness and Growth of India's Textile Industry: Analysis And Policy Options. Economic and Political Weekly, 25:44-45.

- 1990b. Calcutta's Economy 1918-1970: The Fall from Grace.
In: CHAUDHURI, Sukanta (ed.). Calcutta: The Living City. Vol II: The Present and Future. Delhi: OUP.

JOSHI, Chitra. 2003. Lost Worlds. Indian Labour and its Forgotten Histories. Delhi, Permanent Black.

No prelo. Notes on the Breadwinner Debate: Gender and Household Strategies in Working Class Families. Studies in History, 1.

MORRIS, Morris David. 1965. The Emergence of an Industrial Labor Force in India: A Study of the Bombay Cotton Mills, 1854-1947. Bombaim.

NIEHOFF, Arthur. 1959. Factory Workers in India. Milwaukee: Milwaukee Public Museum.

NORONHA, E.; SHARMA, R.N. 1999. Displaced Workers and the Withering of Welfare State. Economic and Political Weekly, 5, junho.

PATEL, Sujata; THORNER, Alice. 1995. Bombay: Metaphor for Modern Índia. Nova Delhi.

Report of the Harijan Survey Committee 1933-34. 1934. Kanpur.

Report of the Study Team on Prohibition, vol II. 1964.

ROY, Tirthankar. 1998. Economic Reforms and Textile Industry in India. Economic and Political Weekly, 33:32.

SHARMA, Kalpana. 2000. Rediscovering Dharavi: Stories from Asia's Largest Slum. Nova Delhi.

VANAMALA, M. 2001. Informalisation and Feminisation of a Formal Sector Industry: A Case Study. Economic and Political Weekly, 36:26, junho-julho. 


\section{Resumo}

Examinando a crise que se abate sobre os grandes centros industriais da Índia desde os anos 1980, o artigo traça uma história social do trabalho nesse país, ressaltando uma dimensão central: a dos múltiplos significados dos espaços de trabalho e de como eles habitam a memória dos trabalhadores.

Privilegiando as vivências desses trabalhadores - nas fábricas e nos bairros, nas cidades e no campo -, a autora traça um amplo e sofisticado quadro das condições de vida e trabalho no país, no qual se combinam tradições e mudanças de forma dinâmica e tensa.

Palavras-chave: espaços de trabalho, memória de trabalhadores, trabalho e comunidade

\section{Abstract}

This article examines the crisis that has taken place in the main industrial cities of India since the 1980s. The author stresses the multiple meanings of the spaces of labor and their relationship with the workers memory as a central feature of the Indian labor history. By taking in strong consideration the everyday life of workers in the factories and neighbourhoods as well as in the urban sites and rural areas, the author offers a broad and sophisticated overview of work and life conditions in that country, where tradition and changes combine in a dynamic and tense way.

Keywords: spaces of labor, workers memory, work and community

\section{Résumé}

En partant de la crise qui s'est abattue sur les grands centres industriels de l'Inde depuis les années 1980, l'article retrace l'histoire du travail social dans ce pays et signale une de ces dimensions centrales: celle des multiples signifiés des espaces de travail et de la place qu'ils occupent dans la mémoire des travailleurs. L'expérience des travailleurs - à l'usine et dans le quartiers, dans les villes et à la campagne - fournit à l'auteur la base pour dessiner un tableau assez large et sophistiqué des conditions de vie et de travail en Inde, un pays dans lequel la tradition et le changement s'associent d'une façon dynamique et pleine de tension.

Mots-clés: espaces de travail, mémoire des travailleurs, travail et communauté 